\title{
Ion Selectivity in Brackish Water Desalination by Reverse Osmosis: Theory, Measurements, and Implications
}

\author{
P.M. Biesheuvel, ${ }^{1}$ L. Zhang, ${ }^{1}$ P. Gasquet, ${ }^{1}$ B. Blankert, ${ }^{2}$ M. Elimelech, ${ }^{3,4}$ and \\ W.G.J. van der Meer ${ }^{*, 5,6}$ \\ ${ }^{1}$ Wetsus, European Centre of Excellence for Sustainable Water Technology, \\ Oostergoweg 9, 8911 MA Leeuwarden, The Netherlands. \\ ${ }^{2}$ King Abdullah University of Science and Technology (KAUST), Water Desalination \\ and Reuse Center (WDRC), Biological and Environmental Science and Engineering \\ Division (BESE), Thuwal 23955-6900, Saudi Arabia. \\ ${ }^{3}$ Department of Chemical and Environmental Engineering, Yale University, New Haven \\ CT 06520-8286, USA. \\ ${ }^{4}$ Nanosystems Engineering Research Center for Nanotechnology-Enabled Water \\ Treatment (NEWT), Yale University, USA. \\ ${ }^{5}$ Oasen Drinking Water Company, Nieuwe Gouwe O.Z. 3, 2801 SB Gouda, The \\ Netherlands. \\ ${ }^{6}$ Membrane Science and Technology, University of Twente, Drienerlolaan 5, 7522 NB \\ Enschede, The Netherlands.
}

\begin{abstract}
Reverse Osmosis (RO) is a membrane-based technology for water desalination. Of paramount importance is the understanding of ion selectivity in mixtures of salts, i.e., to what extent the membrane retains one ion more than another in a multicomponent salt solution. We apply continuum transport theory to describe a large set of data for the ion selectivity of RO membranes treating brackish ground water with more than ten different mono- and divalent ions. The model is based on the Donnan steric partitioning pore model extended to include ions of multiple charge states, such as bicarbonate/carbonic acid, ammonia/ammonium, and the hydroxyl/hydronium ions, and the acid-base reactions between them and with the membrane charge. By adjusting for each ion the ratio of ion size over pore size, we can fit the model to the data. We note that the fitted ion sizes do not always follow a logical order based on the ionic or hydrated size of the ions and that rejection of divalent cations is overestimated in some cases. We discuss possible theoretical improvements to address these discrepancies. Our results highlight the potential of continuum transport theory to describe in detail multicomponent ion transport in RO membranes. The development of a detailed and validated physics-based model is an important step towards achieving improved operation and design of RO-based desalination systems.
\end{abstract}




\section{Introduction}

2 Reverse Osmosis (RO) is a widely used method to desalinate water of high salinity (seawater) 3 and lower salinity (brackish water) by pressing water through a membrane which retains most of the ions [1-4]. Important for the application of RO is an understanding of ion selectivity, which is the question how many of each type of ion are retained by the membrane. In practice, most water resources contain a large number of different ions, and the rejection of these ions by any RO membrane will be very different, with one ion being retained much better than another. Because of the requirement of charge neutrality, inside the membrane and in the permeate, the rejection of a certain ion is not simply a property of the membrane, but also depends on the concentrations and rejections of all other ions, as the data we report also show.

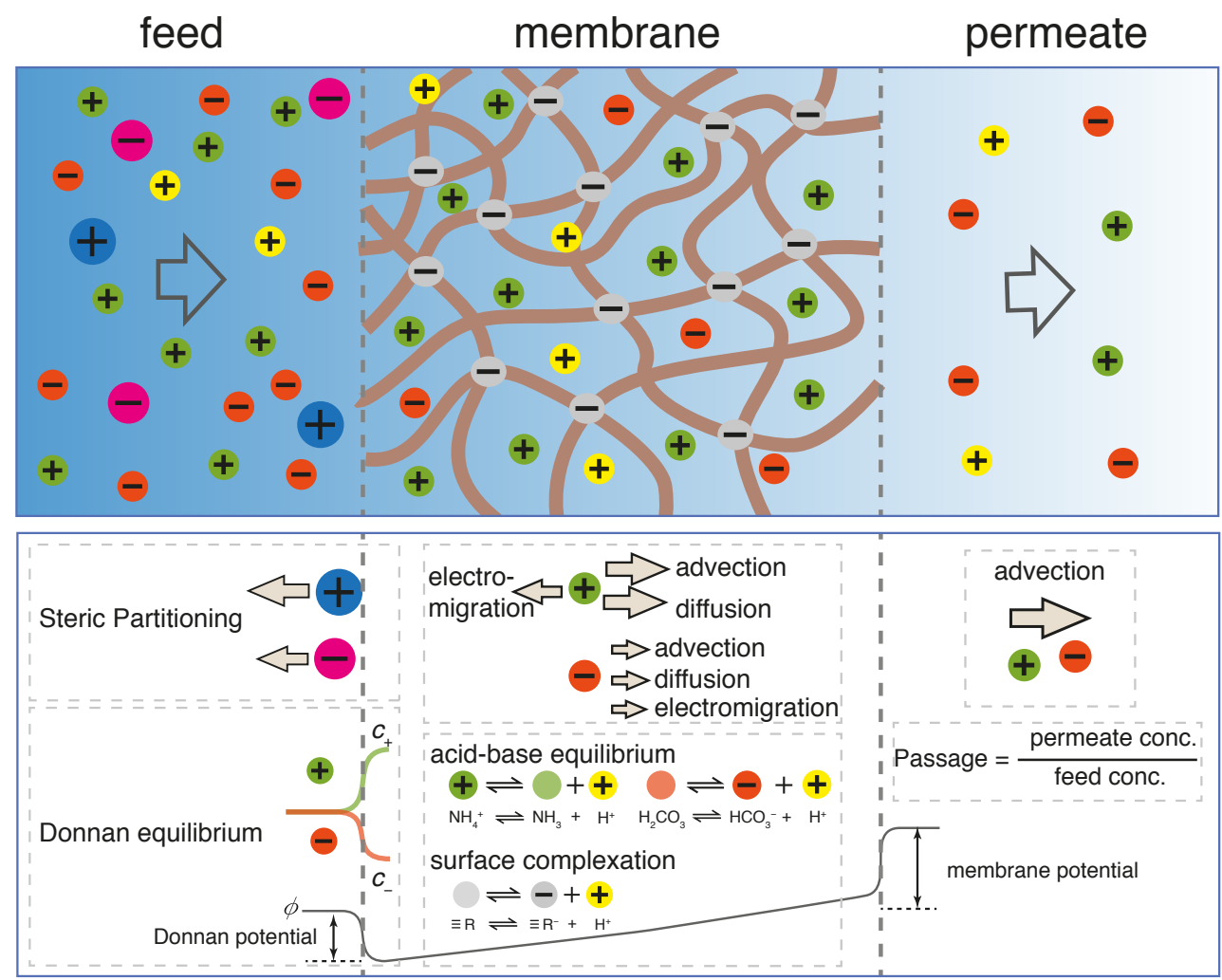

Figure 1: Schematic picture of the extended Donnan Steric Partitioning (ext-DSP) pore model for water desalination with reverse osmosis (RO) membranes, including effects of acid-base reactions.

To understand and predict ion selectivity of RO membranes, detailed theoretical methods are required which include the relevant chemical and physical processes that occur in the membrane. Available calculation softwares provided by commercial parties play an important role in RO process design studies but such softwares do not include a detailed physics-based description of ion rejection in multicomponent ionic systems. Commercial softwares commonly use the solution-diffusion model $[5,6]$ in which ion flow only depends on the ion concentrations in feed and permeate, without considering how the charge of ions and of the membrane influences transport. An extended thermodynamic model also includes ion advection [7]. Acid-base equilibria, such as the reaction of bicarbonate ions with hydronium ions (protons) to form carbonic acid, and the equilibrium between ammonium and ammonia, are not considered in these approaches, and in general, $\mathrm{pH}$ effects are not included or predicted. 
In the present work, we show the usefulness of theory that includes these effects. The local concentration and flow of hydronium and hydroxyl ions are related to the concentration and fluxes of the carbonate and ammonium ions which results in all of these fluxes becoming coupled to one another. The theory we use is the Donnan Steric Partitioning (DSP) pore model [8-14], extended to include water self-ionization and the dependence of membrane charge on local $\mathrm{pH}$, as first put forward by Hall et al. [15, 16], see Figure 1. This we call the extended DSP-model, or ext-DSP model in short. In the present work, we further extend this approach to include all acid-base equilibria between all ionizable species (such as the equilibrium between bicarbonate ions and carbonic acid) [17-19] and we show how the theory can be successfully used to describe data of ion rejection by an $\mathrm{RO}$ module in a groundwater source with around ten different types of ions, several of which participate in acid-base reactions. Related work that also considers $\mathrm{pH}$ effects and acid-base reactions is refs. [20-24], with some differences being that advection is neglected, membrane charge is not considered, and the model formulation uses virtual concentrations. Other related work focusing on extending the classical models, and including membrane charge and reactive ions, is refs. [25,26].

\section{Materials and Methods}

Our study is based on anaerobic groundwater from pumping station "De Hooge Boom" operated by water company Oasen (Kamerik, The Netherlands; located approx. $1.5 \mathrm{~km}$ north-west of the centre of the city of Woerden, along the east side of river De Grecht) [27]. Water is extracted from a sandy layer 15 to $40 \mathrm{~m}$ deep. Because of a layer of peat higher up (which is up to $7 \mathrm{~m}$ thick), the water contains a relatively large concentration of ammonium ions of approx. $3 \mathrm{mg} / \mathrm{L}$. For the ion composition of the water, see Table S.2 in Supporting Information (SI). In the period December 23-26, 2013, the water was treated in a single $4 "$ RO membrane module containing a $7.4 \mathrm{~m}^{2}$ thin film composite (TFC) membrane [28] with a polyamide active layer (ESPA2-LD4040, Hydronautics). The module was placed in a larger RO housing and tested in single pass (no recycle). The inflow volumetric rate is $\Phi_{\mathrm{v}}=1 \mathrm{~m}^{3} / \mathrm{hr}$ and in all experiments $\sim 15 \%$ of this water flows through the membrane. Thus the water flux as directed through the membrane is $20.3 \mathrm{~L} / \mathrm{m}^{2} / \mathrm{hr}$, which implies a water velocity per unit membrane area of $5.6 \mu \mathrm{m} / \mathrm{s}$. The pressure difference across the membrane is approx. 9.6 bar.

RO experiments are done for different compositions of the feedwater. Case I is the original groundwater which has an ionic strength of $\sim 14 \mathrm{mM}$ and a concentration ratio $\left[\mathrm{Na}^{+}\right]_{\text {in }} /\left[\mathrm{Ca}^{2+}\right]_{\text {in }}$ of $\sim 0.86$, see Table S.2. For conditions II to IV, the ionic strength is increased by $\sim 75 \%$ to $\sim 24$ $\mathrm{mM}$, in three different ways. In case II the feed concentration of $\mathrm{Ca}^{2+}$ is increased about twofold, by addition of $\sim 3.3 \mathrm{mM} \mathrm{CaCl} 2$. Thus the $\mathrm{Na}^{+} / \mathrm{Ca}^{2+}$ concentration ratio is reduced by a factor of two. In case III both $\left[\mathrm{Ca}^{2+}\right]_{\text {in }}$ and $\left[\mathrm{Na}^{+}\right]_{\text {in }}$ are roughly doubled by the addition of $\sim 2.5 \mathrm{mM} \mathrm{CaCl}$ and $\sim 2.5 \mathrm{mM} \mathrm{NaCl}$ which keeps the $\mathrm{Na}^{+} / \mathrm{Ca}^{2+}$ concentration ratio close to the original value. Finally, in case IV the concentration of $\mathrm{Na}^{+}$is increased roughly fourfold by addition of $\sim 6.6 \mathrm{mM}$ $\mathrm{Na}_{2} \mathrm{SO}_{4}$ and thus the $\mathrm{Na}^{+} / \mathrm{Ca}^{2+}$-concentration rate is increased four times as well. Thus, from case II to III to IV, while the ionic strength stays the same, the $\mathrm{Na}^{+} / \mathrm{Ca}^{2+}$-concentration ratio of the feedwater increases eightfold. Each experiment is done three times, see Tables S.2 and S.3. In the inflow and permeate, $\mathrm{pH}$ is measured as well as concentrations of $\mathrm{Na}^{+}, \mathrm{K}^{+}, \mathrm{NH}_{4}^{+}, \mathrm{Ca}^{2+}$, $\mathrm{Mg}^{2+}, \mathrm{Cl}^{-}, \mathrm{HCO}_{3}{ }^{-}, \mathrm{SO}_{4}{ }^{2-}$, and three other ions present at low concentration. See SI for details on data analysis, with all data presented in Tables S.2 and S.3. 


\section{Theory}

The ext-DSP model is based on the extended Nernst-Planck equation which includes ion diffusion, (electro-)migration, and advection as driving forces acting on the ions, see Figure 1. The model is described in detail in the Supporting Information. Advection is the flow of ions because they are carried along by the water which is pressed through the membrane, while diffusion and migration refer to ion transport because of gradients in ion concentration and electrical potential, respectively. Gradients in the electrical potential are generated in the transport process to enhance the velocity of some ions, reduce it for others, such that ultimately the number of pluscharges moving through the membrane equals the number of minus-charges (condition of zero electrical current). In this way, the transport of one ion influences that of all others, i.e., the transport rates of all ions are coupled. The membrane is charged and because of local charge neutrality it therefore influences the local concentration of all ions [29-31]. The DSP model combines a description of ion transport with equilibrium models for ion partitioning at the membrane-solution interfaces. Hindrance functions for diffusion and convection are included in the transport equations, and they are a function of the ratio of ion size over pore size, $\lambda$, a factor which is different for each ion. These factors $\lambda$ also influence the partitioning of the ion at the outer edges of the membrane (the active layer, or selective layer, of the TFC RO membrane). Like in ref. [15, 16, 19], we extend the DSP model by including all acid-base reactions between ions, and the equilibrium between ions (particularly, hydronium ions) with the fixed membrane charge [32]. Whereas in ref. $[15,16]$ the only acid-base reaction in solution is that between $\mathrm{H}^{+}$and $\mathrm{OH}^{-}$, with three other ions considered as inert species, and while ref. [19] focused on seawater and model development, in the present work we compare in detail the ext-DSP model with experimental data of water desalination by an $\mathrm{RO}$ membrane of a groundwater source which contains around ten types of ions, several of which participate in acid-base reactions. The experiments were done at a low water recovery (only $15 \%$ of the inflow water permeates through the membrane), and thus the feed solution on the upstream side (retentate side) is not being concentrated much while water is pressed through the membrane. Therefore, in our model, we only need to set up and solve the equations in the direction through the membrane, and we do not need to describe the full two-dimensional geometry of a complete RO module. In the present model we only describe the active layer of TFC RO membrane, which is approx. 100 to $200 \mathrm{~nm}$ thick [30,33], together with the two Donnan layers on each side of this active layer. We neglect concentration polarization (CP) on the retentate side [34-36].

\section{Results and Discussion}

As discussed, a series of RO experiments was conducted with a groundwater source containing around ten types of monovalent and divalent ions, of which removal of ammonium and ammonia was of particular relevance for downstream operation. In addition, experiments were done with water that was spiked with extra monovalent and divalent cations and anions. The ionic composition of the permeate (effluent) was measured and for each ion the passage, $P$, was calculated, which is the ratio of concentration in the effluent over that in the feed, and which relates to ion rejection by $P=1-R$. Figure 2 shows data for passage, $P$, for the four cases discussed, which is case I for the original groundwater (blue, ionic strength $\sim 14 \mathrm{mM}$ ), and cases II-IV (red) with a higher ionic strength $(\sim 24 \mathrm{mM}$ for all three cases $)$ and different feed $\left[\mathrm{Na}^{+}\right] /\left[\mathrm{Ca}^{2+}\right]$ ratio, from low in case II to high in case IV. Figure 2 also shows theoretical predictions of the ext-DSP model 
which describe most of the experimental data very well. This good fit was obtained by tuning for all ions the size factor $\lambda$, which determines for each ion the partitioning coefficient $\Phi$, and hindrance functions, $K_{\mathrm{d}}$ and $K_{\mathrm{c}}$, as well as factors for tortuosity and membrane charge, see Table S.1. These parameters are discussed in detail in SI. Only for case III and IV, the passage of divalent cations is underestimated, while for $\mathrm{SO}_{4}{ }^{2-}$ we do not have sufficient data to assess the validity of the model.

One of the most interesting observations in the data presented in Figure 2 is that the passage (or, rejection) of cations depends strongly on the feed $\left[\mathrm{Na}^{+}\right] /\left[\mathrm{Ca}^{2+}\right]$-ratio, see panels a)-c) in Figure 2 for monovalent cations, and panels d)-e) for divalent cations, while for the monovalent anions the passage does not depend much on this ratio, see third row in Figure 2. This difference between how anions and cations respond to the feed $\left[\mathrm{Na}^{+}\right] /\left[\mathrm{Ca}^{2+}\right]$ - ratio seems counterintuitive, because the membrane must pass equal numbers of positive charges as negative charges, such that the total current through the membrane remains zero. So how can passage go down for cations with increasing feed $\left[\mathrm{Na}^{+}\right] /\left[\mathrm{Ca}^{2+}\right]$-ratio, but not for anions? As it turns out, the ext-DSP model reproduces the experimental observation that the passage, $P$, of cations strongly depends on the $\mathrm{Na}^{+} / \mathrm{Ca}^{2+}$ concentration ratio, while at the same time for the anions $P$ is pretty much always the same. Though we do not have an intuitive explanation for the origin of this difference between anions and cations, most certainly no error is made in the analysis. This is better explained in Figure S.3 which presents the permeate concentration which according to Eq. (S.5) is proportional to the ion flux (for inert species). In Figure S.3 we notice that for case II (lower $\mathrm{Na}^{+} / \mathrm{Ca}^{2+}$ ratio), the flux of $\mathrm{Cl}^{-}$is larger than for case I, to compensate for the higher cation fluxes (than in case I), while for case IV, the fluxes of monovalent anions do not change when compared with case $\mathrm{I}$, and an increase in the flux of $\mathrm{Na}^{+}$is compensated by a decline in the flux of other cations and an increase in the sulphate flux. In all of these situations (both experimentally and in the calculations), the total ionic current running through the membrane is always zero, with an equal membrane flux of cationic and anionic charge.

The values that we find for the ion size (thus for the size factor $\lambda$ ) to fit the model to the data, see Table S.1, are reasonable, in that the ion sizes are a significant fraction of the pore size, but these values for the ion size do not follow much of a logical order. Note that in the present model we simply assign one value of $\lambda$ to each ion irrespective of whether this value should correlate more to the hydrated ion size, or the Stokes ion size [37]. The absence of a logical order in the ion sizes leads us to conclude that our current approach is insufficient, to use the ion size-pore size ratio, $\lambda$, as the sole parameter for each ion to uniquely describe the three parameters, $\Phi, K_{\mathrm{c}}$ and $K_{\mathrm{d}}$. Especially the partitioning coefficient, $\Phi$, will have additional contributions besides a pure volumetric size exclusion effect, such as related to ion dehydration [38]. Molecular simulations on the hydration state of ions while passing through sub-nm pores may shed light on the suitability of using the size factor, $\lambda$, to determine ion mobility and hindrance in the active layer of an RO membrane [39]. Thus, for each ion, $\Phi$ is best fitted separately from the hindrance functions $K_{\mathrm{c}}$ and $K_{\mathrm{d}}$. Studies on equilibrium ion absorption in polyamide porous materials may also help to find proper values for the $\Phi$-factors for each ion [33], while controlled laboratory experiments using membrane coupons (not modules) for systems without acid-base chemistry are essential to study the mobility of ions in the membrane. Furthermore, when discussing how to improve the model, it is a relevant question whether the hindrance functions are a good method to determine $K_{\mathrm{c}}$ and $K_{\mathrm{d}}$. A friction-based approach to derive the extended Nernst-Planck equation leads to the conclusion that $K_{\mathrm{c}}<1$, see ref. [40], in contrast to the hydrodynamic theory which predicts $K_{\mathrm{c}}>1$ [41]. To improve the model, it is also useful to revisit the relationship between membrane 
charge and $\mathrm{pH}$ which must be based on the local $\mathrm{pH}$ inside the membrane pores. Also binding of divalent cations such as $\mathrm{Ca}^{2+}$ to the negative fixed charges in the membrane can play a role [15, 16]. The relevance of the concentration polarization layer must also be investigated. Additional experimental work at different permeate flow rates and values of the feed $\mathrm{pH}$ will generate more data to critically test the ext-DSP model.

The ext-DSP model generates a prediction for all profiles of concentration and ion fluxes across the membrane, of which we give several examples in Figure 3 as function of the nondimensional coordinate, $x$, which runs from $x=0$ at the retentate side, to $x=1$ at the permeate side of the membrane. Note that the profiles presented in Figure 3 are just theoretical predictions, and mainly serve to illustrate that across the membrane (even if only a fraction of $1 \mu \mathrm{m}$ thickness), strong changes in concentrations, fluxes and reaction rates likely occur. The profiles in these properties can probably not be directly probed experimentally in much detail during RO operation, but still, these profiles are the output of the same model which predicts the macroscopic observations of ion rejection as presented in Figure 2, which compare favorably with data. Changes in concentration across the membrane by up to a factor of 1000 are calculated, e.g. for $\mathrm{NH}_{3}$ and $\mathrm{H}^{+}$. As also Figure $\mathrm{S} 4$ shows, for the ions $\mathrm{Na}^{+}$and $\mathrm{Cl}^{-}$, the predicted concentration profiles are not monotonically increasing or decreasing, but local minima and maxima are found about halfway into the membrane. Molar fluxes across the membrane are invariant for all inert species, but the calculated flux for three reactive ions are presented in Figure 3d showing how fluxes can change from close to zero at one side of the membrane to an appreciable value on the other side. When the flux, $J_{i}$, changes, the reaction rate, $R_{i}$, is non-zero at that position for the ions involved, see Figure 3e for the carbonate-system as well as for the ammonia-system. Finally, the membrane charge, $X$, and the electrical potential, $V$, are presented in Figure 3f, showing also the Donnan potential drops at the two membrane-solution edges (at $x=0,1$ ) [42].

In conclusion, the DSP model, extended to include acid-base reactions between ions and with the membrane charge, was evaluated to describe experimental data of brackish water desalination in a reverse osmosis module. There is uncertainty about the values of the parameters in the calculations and the equations to relate ion size to partitioning and hindrance functions. These correlations must be addressed in future work. Nevertheless, we conclude that the extended DSP model is a suitable and effective framework to describe rejection of ions in an RO process treating water containing many types of ions. In future work, the ext-DSP model can be the basis for a realistic two-dimensional description of an $\mathrm{RO}$ module, and this code can be included in design software for a complete RO-based water treatment facility. Thus, the ext-DSP model offers the possibility to significantly improve the accuracy of physical understanding of RO membrane systems both for high and low salinity water streams. 

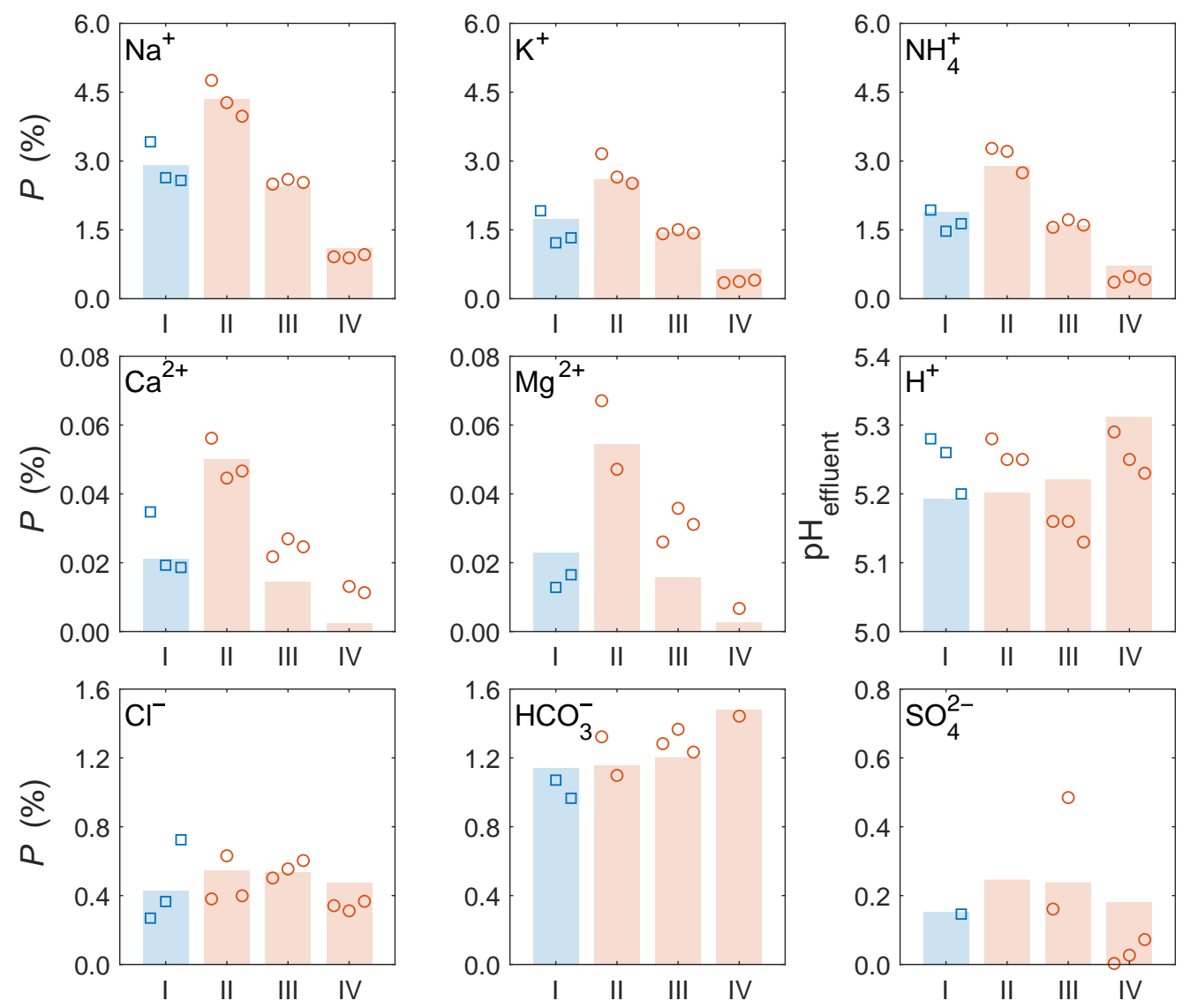

Figure 2: Experimental data (squares and circles) and model predictions (bars) of passage, $P$, for desalination of groundwater with RO membranes of eight ion types, as well as permeate $\mathrm{pH}$ (passage $P$ equals $100 \%$ minus rejection, $R$ ). Case $\mathrm{I}$ is the source water (ionic strength $\sim 14 \mathrm{mM}$ ) while cases II-IV represent water with additional salts such that the ionic strength in these three cases is increased to $\sim 24 \mathrm{mM}$. These three cases are distinguished by having a different ratio of the feed concentration of $\mathrm{Na}^{+}$over $\mathrm{Ca}^{2+}$, from case II with a value of this ratio half of the original water, to about equal (case III), to a fourfold increase (case IV). See main text for further details. 

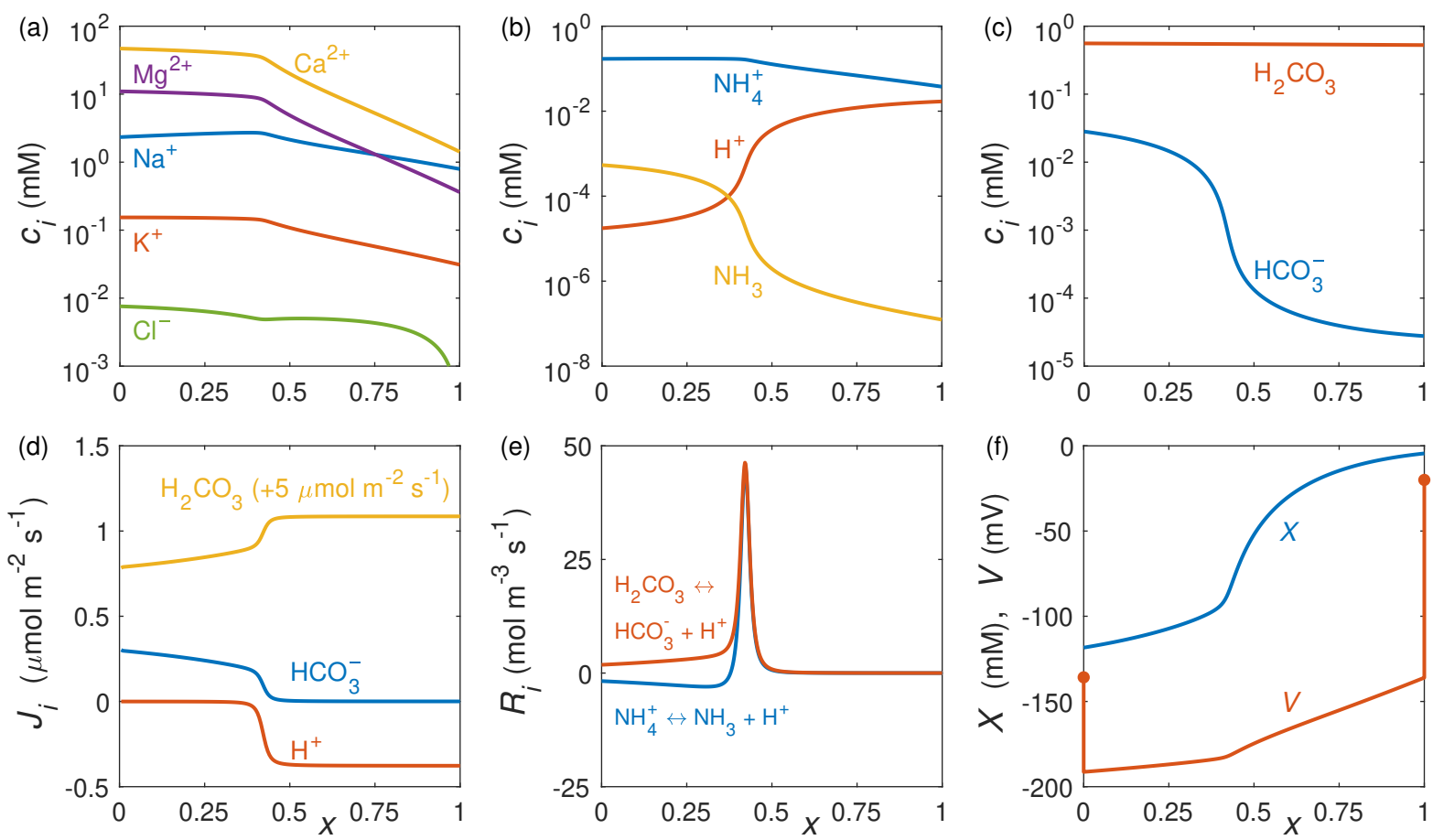

Figure 3: Calculated profiles across the active layer of an RO membrane of a-c) ion concentration, d) ion flux, $J_{i}$, of reactive species, e) reaction rates, $R_{i}$, of acid-base reactions, and f) membrane charge density, $X$, and electrical potential, $V$, as function of normalized position (reference condition I, see Table S.4).

\section{Associated Content}

The Supporting Information is available free of charge on the ACS Publications website at DOI:10.1021/acs.es-tlett.xxx. SI presents a detailed description of the extended DSP model, the data analysis procedure, the model-to-data fitting approach, and additional calculation results of ion concentration and fluxes across the membrane.

\section{Author Information}

Corresponding Author W.G.J. van der Meer, Oasen Drinking Water Company, Nieuwe Gouwe O.Z. 3, 2801 SB Gouda, The Netherlands. *E-mail:w.g.j.vandermeer@utwente.nl

\section{ORCID}

P.M. Biesheuvel 0000-0002-5468-559X
L. Zhang
0000-0003-2836-794X

198

B. Blankert

0000-0003-0349-5099

M. Elimelech

0000-0003-4186-1563

W.G.J. van der Meer

0000-0002-9278-840X

Notes

The authors declare no competing financial interest. 


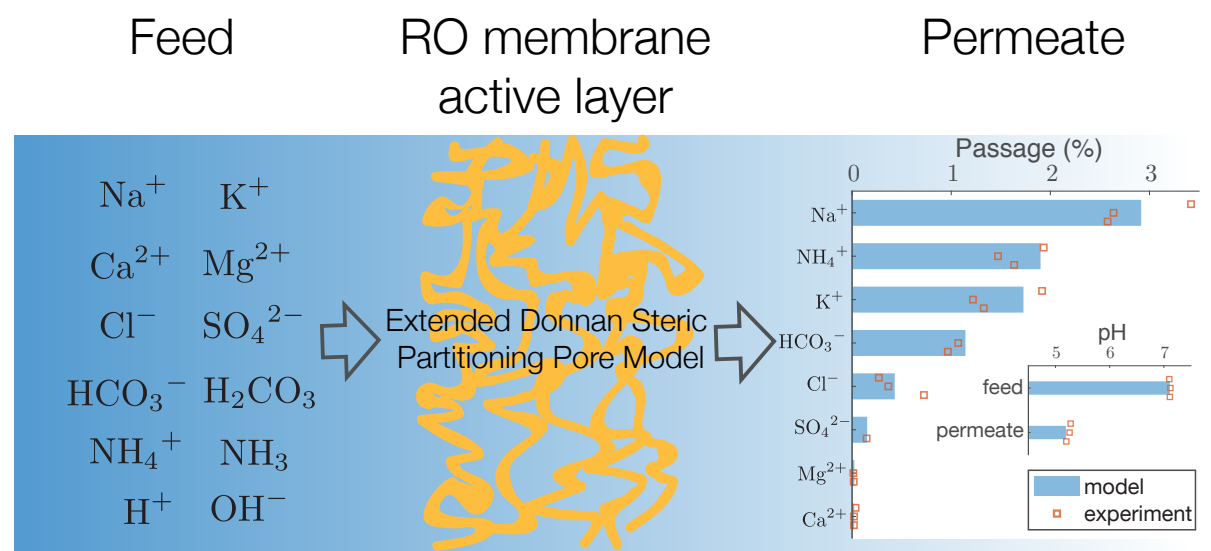

\section{Acknowledgments}

Part of this work was performed in the cooperation framework of Wetsus, European Centre of Excellence for Sustainable Water Technology (www.wetsus.eu). Wetsus is co-funded by the Dutch Ministry of Economic Affairs and Climate Policy, the Northern Netherlands Provinces, and the Province of Fryslân. The authors thank the participants in the research theme Advanced Water Treatment for fruitful discussions and financial support.

\section{References}

[1] Baker, R.W. Reverse Osmosis. Membrane Technology and Applications, 2004, 2nd Ed., Wiley, NY, 191-235.

[2] Fritzmann, C.; Löwenberg, J.; Wintgens, T.;Melin, T. State-of-the-art of reverse osmosis desalination, Desalination 2007, 216, 1-76.

[3] Elimelech, M.; Phillip, W. A. The Future of Seawater Desalination: Energy, Technology, and the Environment. Science 2011, 333, 712-717.

[4] Werber, J.R.; Deshmukh, A.; Elimelech, M. The critical need for increased selectivity, not increased water permeability, for desalination membranes. ES\&T Lett. 2016, 3, 112-120.

[5] Lonsdale, H.K.; Merten, U.; Riley, R.L. Transport properties of cellulose acetate osmotic membranes. J. Appl. Polymer Sci. 1965, 9, 1341-1362.

[6] Wijmans, J.G.; Baker, R. W. The Solution-Diffusion Model - a Review. J. Membrane Sci. 1995, $107,1-21$. 
[7] Spiegler, K.S.; Kedem, O. Thermodynamics of hyperfiltration (reverse osmosis): criteria for efficient membranes. Desalination 1966, 1, 311-326.

[8] Bowen, W.R.; Mukhtar, H. Characterisation and prediction of separation performance of nanofiltration membranes. J. Membrane Sci. 1996, 112, 263-274.

[9] Bowen, W.R.; Mohammad, A.W.; Hilal, N. .Characterisation of nanofiltration membranes for predictive purposes - Use of salts, uncharged solutes and atomic force microscopy. $J$. Membrane Sci. 1997, 126, 91-105.

[10] Bandini, S.; Vezzani, D. Nanofiltration modeling: The role of dielectric exclusion in membrane characterization. Chem. Eng. Sci. 2003, 58, 3303-3326.

[11] Szymczyk, A.; Fievet, P. Investigating transport properties of nanofiltration membranes by means of a steric, electric and dielectric exclusion model. J. Membrane Sci. 2005, 252, 7788.

[12] Lanteri, Y.; Fievet, P.; Szymczyk, A. Evaluation of the steric, electric, and dielectric exclusion model on the basis of salt rejection rate and membrane potential measurements. J. Colloid Interface Sci. 2009, 331, 148-155.

[13] Saliha, B.; Fievet, P.; Szymczyk, A. Investigating nanofiltration of multi-ionic solutions using the steric, electric and dielectric exclusion model. Chem. Eng. Sci. 2009, 64, 3789-3798.

[14] Déon, S.; Escoda, A.; Fievet, P. A transport model considering charge adsorption inside pores to describe salts rejection by nanofiltration membranes. Chem. Eng. Sci. 2011, 66, $2823-2832$.

[15] Hall, M.S.; Starov, V.M.; Lloyd, D.G. Reverse osmosis of multicomponent electrolyte solutions. Part I. Theoretical development. J. Membrane Sci. 1997, 128, $23-37$.

[16] Hall, M.S.; Lloyd, D.R.; Starov. V.M. Reverse osmosis of multicomponent electrolyte solutions Part II. Experimental verification. J. Membrane Sci. 1997, 128, 39-53.

[17] Dykstra, J.E.; Biesheuvel, P.M.; Bruning, H.; Ter Heijne, A. Theory of ion transport with fast acid-base equilibrations in bioelectrochemical systems. Phys. Rev. E 2014, 90, 013302.

[18] Dykstra, J.E.; Keesman, K.J.; Biesheuvel, P.M.; Van Der Wal, A. Theory of pH changes in water desalination by capacitive deionization. Water Research 2017, 119, 178-186.

[19] Oren, Y.; Biesheuvel, P.M. Theory of Ion and Water Transport in Reverse-Osmosis Membranes. Phys. Rev. Appl. 2018, 9, 024034.

[20] Nir, O.; Fridman Bishop, N.; Lahav, O.; Freger, V. Modeling pH variation in reverse osmosis. Water Research 2015, 87, 328-335.

[21] Nir, O.; Lahav, O. Coupling mass transport and chemical equilibrium models for improving the prediction of SWRO permeate boron concentrations. Desalination 2013, 310, 87-92.

[22] Nir, O.; Lahav, O. Modeling weak acids' reactive transport in reverse osmosis processes: A general framework and case studies for SWRO. Desalination 2014, 343, 147-153. 
[23] Nir, O.; Ophek, L.; Lahav, O. Acid-base dynamics in seawater reverse osmosis: Experimental evaluation of a reactive transport algorithm. Environm. Sci.: Water Res. Techn. 2016, 2, 107-116.

[24] López, J.; Reig, M.; Yaroshchuk, A.; Licon, E.; Gibert, O.; Cortina, J.L. Experimental and theoretical study of nanofiltration of weak electrolytes: $\mathrm{SO}_{4}^{2-} / \mathrm{HSO}_{4}^{-} / \mathrm{H}^{+}$system. J. Membrane Sci. 2018, 550, 389-398.

[25] Kezia, K.; Lee, J.; Hill, A.J.; Kentish, S.E. Convective transport of boron through a brackish water reverse osmosis membrane. J. Membrane Sci. 2013, 445, 160-169.

[26] Kezia, K.; Lee, J.; Ogieglo, W.; Hill, A.; Benes, N.E.; Kentish, S.E. The transport of hydronium and hydroxide ions through reverse osmosis membranes. J. Membrane Sci. 2014, 459, 197-206.

[27] Albergamo, V.; Blankert, B.; Cornelissen, E.R.; Hofs, B.; Knibbe, W.-J.; Van der Meer, W.G.J.; De Voogt, P. Removal of polar organic micropollutants by pilot-scale reverse osmosis drinking water treatment. Water Research 2019, 148, 535-545.

[28] Petersen, R.J. Composite reverse osmosis and nanofiltration membranes J. Membrane Sci. 1993, 83, 81-150.

[29] Childress, A.E.; Elimelech, M. Effect of solution chemistry on the surface charge of polymeric reverse osmosis and nanofiltration membranes. J. Membrane Sci. 1996, 119, 253-268.

[30] Coronell, O.; Mariñas, B.J.; Zhang, X.; Cahill, D.G. Quantification of functional groups and modeling of their ionization behavior in the active layer of FT30 reverse osmosis membrane. Env. Sci. Techn. 2008, 42, 5260-5266.

[31] Bruni, L.; Bandini, S. The role of the electrolyte on the mechanism of charge formation in polyamide nanofiltration membranes. J. Membrane Sci. 2008, 308, 136-151.

[32] Zhang, L.; Biesheuvel, P.M.; Ryzhkov, I.I. Theory of ion and water transport in electronconducting membrane pores with $\mathrm{pH}$-dependent chemical charge. Phys. Rev. Applied 2019, 12,014039 .

[33] Zhang, X.; Cahill, D.G.; Coronell, O.; Mariñas, B.J. Partitioning of salt ions in FT30 reverse osmosis membranes. Appl. Phys. Lett. 2007, 91, 181904.

[34] Brian, P.L.T. Mass transport in reverse osmosis. Desalination by Reverse Osmosis, Ed. U. Merten, MIT Press, Cambridge, 1966, 161-202.

[35] Kim, S.; Hoek, E.M.V. Modeling concentration polarization in reverse osmosis processes. Desalination 2005, 186, 111-128.

[36] Jang, E.S.; Mickols, W.; Sujanani, R.; Helenic, A.; Dilenschneider, Th.J.; Kamcev, J. ; Paul, D.R.; Freeman, B.D. Influence of Concentration Polarization and Thermodynamic Nonideality on Salt Transport in Reverse Osmosis Membranes. J. Membrane Sci. 2019, 572, 668-675.

[37] Nightingale, E.R. Phenomenological Theory of Ion Solvation. Effective Radii of Hydrated Ions. J. Phys. Chem. 1959, 63, 1381-1387. 
[38] Epsztein, R.; Shaulsky, E.; Qin, M.; Elimelech, M. Activation behavior for ion permeation in ionexchange membranes: Role of ion dehydration in selective transport. J. Membrane Sci. 2019, 580, 316-326.

[39] Faucher, S.; Aluru, N.; Bazant, M.Z.; Blankschtein, D.; Brozena, A.H.; Cumings, J.; de Souza, J.P.; Elimelech, M.; Epsztein, R.; Fourkas, J.T.; et al. Critical Knowledge Gaps in Mass Transport Through Single-Digit Nanopores: A Review and Perspective. J. Phys. Chem. C 2019, 123, 21309-26.

[40] Tedesco, M.; Hamelers, H.V.M.; Biesheuvel, P.M. Nernst-Planck transport theory for (reverse) electrodialysis: II. Effect of water transport through ion-exchange membranes. $J$. Membrane Sci. 2017, 531, 172-182.

[41] Dechadilok P.; Deen, W.M. Hindrance Factors for Diffusion and Convection in Pores. Ind. Eng. Chem. Res. 2006, 45, 6953-6959.

[42] Matsumoto, H.; Konosu, Y.; Kimura, N.; Minagawa, M.; Tanioka, A. Membrane potential across reverse osmosis membranes under pressure gradient. J. Colloid Interface Sci. 2007, 309, 272-278. 